\title{
Review Article \\ Current Cigarette Smoking and Its Predictors among School-Going Adolescents in East Africa: A Systematic Review and Meta-Analysis
}

\author{
Nega Tezera (iD) and Aklilu Endalamaw \\ Department of Pediatrics and Child Health Nursing, School of Nursing, College of Medicine and Health Sciences, \\ University of Gondar, Gondar, Ethiopia
}

Correspondence should be addressed to Nega Tezera; edomnega4@gmail.com

Received 16 February 2019; Revised 30 March 2019; Accepted 2 April 2019; Published 8 May 2019

Academic Editor: Alessandro Mussa

Copyright (c) 2019 Nega Tezera and Aklilu Endalamaw. This is an open access article distributed under the Creative Commons Attribution License, which permits unrestricted use, distribution, and reproduction in any medium, provided the original work is properly cited.

Background. In developing countries, tobacco smoking has its own contribution to the burden of noncommunicable causes of morbidity and mortality. Studies estimated the burden of cigarette smoking among school-going adolescents in different geographical areas of East Africa. However, due to discrepancies found among those different findings, there is no representative data about the burden of smoking in the continent. Objectives. This systematic review and meta-analysis aimed to assess the pooled prevalence of current cigarette smoking and its associated factors among school-going adolescents in East Africa. Methods. PubMed, Google Scholar, and the Web of Science Library were searched to access included articles. A weighted inverse-variance random-effects model was used to estimate the prevalence of current cigarette smoking. Variations in the pooled estimates of the prevalence were adjusted through subgroup analysis according to the specific country, where the study was conducted. Funnel plot and Egger's regression test were used to check publication bias. STATA version 14 statistical software was used for metaanalysis. Results. A total of 26,875 school-going adolescents were included. The pooled prevalence of current cigarette smoking among school-going adolescents in East Africa was found to be 9.02\% (95\%CI: 6.34-11.70). Based on the subgroup analysis, current cigarette smoking among school-going adolescents was estimated at 9.8\% in Kenya, 7.72\% in Ethiopia, 10.83\% in Uganda, $13.6 \%$ in Sudan, and 4\% in Tanzania. Conclusions. This meta-analysis revealed that the prevalence of current cigarette smoking is increasing among school-going adolescents in East Africa. Therefore, countries have to realize sale prevention policies, establishing and/or strengthening antismoking campaigners designed for school-going adolescents, and providing training for teachers to be antismoking campaigners.

\section{Background}

Tobacco smoking is one of the notable public health threats killing more people than HIV/AIDS, tuberculosis, and malaria in the world. It is projected that by the end of 2030, the number of deaths would increase by 8 million per year and could account for $10 \%$ of the total global mortality by 2020 , killing nearly one billion people $[1,2]$.

Moreover, in developing countries, tobacco smoking has been responsible for an increasing burden of noncommunicable causes of deaths and diseases [3, 4]. Evidence shows that sustained tobacco use leads to different health consequences due to exposure to nicotine $[5,6]$. For instance, major depression, anxiety, periodontal, peripheral, vascular, and heart disease, stroke, chronic obstructive pulmonary disease, pneumonia, and lung cancers have been recorded among cigarette smokers [7-10]. Moreover, smoking also exposed smokers to many risky behaviors, like fighting and unprotected sex [11].

In the world, many adults mostly begin to smoke at the age of adolescence, the period at which young people are usually exposed to tobacco experimentation and/or smoking their first cigarettes $[5,6]$. Today, more than 600,000 and 3 million middle- and high-school students have experienced smoking cigarettes, respectively $[12,13]$. Worldwide, sustainable development goals have been planned to reduce 
cigarette smoking by implementing different strategies like advertising restrictions, changing policies, and implementing school health education and community advocacy programs. For example, a school-based program can reduce shortterm smoking prevalence in the range of $30 \%-70 \%$. This program can save approximately between 2,000 and 20,000 US\$ per QALY in contrast with the total cost needed for other interventions, which ranges from 16,400 to 580,000 US\$ [14]. Despite the implementation of adolescent-focused strategies, cigarette smoking was reported as $51 \%$ in southern Brazil [15], $10.7 \%$ to $14.7 \%$ in Taiwan [16], and $15.5 \%$ in Africa [17].

The easy accessibility of tobacco, traditions and moderate pricing, peer and family influence, and tobacco company advertisements and promotional activities [18] are some of the predisposing factors to cigarette smoking among adolescents. Besides, male sex, age, type of school, alcohol use, no exposure to antismoking media messages, lack of attention at schools, exposure to the movies with smoker actors, and smoker teachers [19-29] are identified associated factors from previous studies.

Investing on the prevention of young people from smoking is the sole strategy to mitigate the health consequences [30]. According to research, East Africa falls in the range of $4 \%$ to $32 \%$ by the magnitude of school-going adolescent smokers although there have been no continent-based representative data. Therefore, this study aimed to estimate the overall prevalence of current cigarette smoking and its associated factors among school-going adolescents in East Africa in order to contribute to a continent-based policy formulation.

\section{Method and Materials}

2.1. Reporting. The result of this review was reported in accordance with the Preferred Reporting Items for Systematic Reviews and Meta-Analyses guideline (PRISMA) [31] (PRISMA checklist), and it is registered in the Prospero database (PROSPERO 2018 [CRD42018096283]) accessed at https://www.crd.york.ac.uk/prospero/\#searchadvanced.

2.2. Information Source and Search Strategy. We searched all published studies reporting with the prevalence and/or associated factors of cigarette smoking among school-going adolescents in East African countries.

PubMed, Google Scholar, and Web of Science library were searched. Search strategies were established using "AND" and/or "OR" Boolean operators. The search strategy for PubMed was Adolescent [MeSH Terms] OR youth OR children OR young OR AND predictors [MeSH Terms] OR risk factors OR enablers OR determinants OR covariates OR associated factors OR predisposing factors OR factors AND prevalence [MeSH Terms] OR burden OR incidence OR magnitude OR epidemiology AND tobacco smoking [MeSH Terms] OR cigarette smoking OR smoking OR cigar OR substance use OR substance abuse AND East Africa.

2.3. Study Inclusion Criteria. Studies were included if and only if they fulfilled the following criteria.
Study design: the search was designed to access crosssectional, cohort, and case-control studies. Participants: this systematic review considered school-going adolescents or young students.

Studies which reported the prevalence and/or at least one associated factor were included.

Language: studies published in English were included.

2.4. Exclusion Criteria. Studies conducted other than adolescent students, editorial comments, conference proceedings, and qualitatively described works were excluded.

2.5. Quality Assessment Tool. Two critical appraisers (NT, AE) autonomously assessed the quality of the study using the Joanna Briggs Institute Meta-Analysis of Statistics Assessment and Review Instrument (JBI-MAStARI) [32]. The JBI critical appraisal checklist tool for cross-sectional studies which consists of eight criteria was used. These are (1) defined criteria for inclusion, (2) described study subject and the setting, (3) exposure measured in a valid and reliable method, (4) stated objective and standard criteria for measurement, (5) identified confounding factors, (6) stated strategies for confounding factors, (7) outcome measurement, and (8) appropriate statistical analysis used. Studies which scored $50 \%$ and above of the quality assessment criteria were considered low-risk bias.

2.6. Data Abstraction Tool and Process. Two authors (N.T \& A.E) independently reviewed abstracts and full-text articles, using a preestablished data abstraction tool. Data were extracted by Microsoft Office Excel 2007. The name of the first author, the country where research was conducted, study design, study setting, the age of study participants, the year of study, and sample size were extracted. Whenever disagreement happened, it was resolved by discussion and/or repeating the procedure.

2.7. Measurement of Outcome. Current cigarette smoking was defined as "having smoked at least once in the past 30 days."

The prevalence of cigarette smoking was determined by dividing who were smoking at the moment by the overall participants of the study.

2.8. Statistical Analysis. A weighted inverse-variance random-effects model [33] was used to estimate the prevalence of smoking. The variation in the pooled estimates of the prevalence was adjusted through subgroup analysis according to the country, where the included studies were conducted. Heterogeneity across studies was considered low, moderate, and high when an $\mathrm{I}^{2}$ statistic value denoted $25 \%, 50 \%$, and $75 \%$, respectively [34]. Funnel plot and Egger's regression test were used to check publication bias [35]. STATA version 14 statistical software was used for meta-analysis. The sensitivity analysis was also applied to see the impact of every single study on the overall estimate. Factors significantly associated with the reported adjusted odds ratio were described qualitatively. 
TABLE 1: Characteristics of systemic review and meta-analysis articles $(n=10)$.

\begin{tabular}{|c|c|c|c|c|c|}
\hline Author/Year & Study Area & Study design & Sample size & $\begin{array}{l}\text { Prevalence }(95 \% \mathrm{CI}) \\
\text { of cigarette smoking }\end{array}$ & Quality \\
\hline William K.et al/2007[26] & Kenya & $\begin{array}{l}\text { Cross- } \\
\text { sectional }\end{array}$ & 12378 & 9.8 & Low risk \\
\hline Ayalu A.et al/2012[21] & Ethiopia & $\begin{array}{l}\text { Cross- } \\
\text { sectional }\end{array}$ & 1721 & 4.2 & Low risk \\
\hline Emmanuel R. et al/2007[23] & Ethiopia & $\begin{array}{l}\text { Cross- } \\
\text { sectional }\end{array}$ & 1868 & 2.9 & Low risk \\
\hline Anteneh M. et al/2012[22] & Ethiopia & $\begin{array}{l}\text { Cross- } \\
\text { sectional }\end{array}$ & 651 & 6.8 & Low risk \\
\hline Lilian M. et al/2004[20] & Uganda & $\begin{array}{l}\text { Cross- } \\
\text { sectional }\end{array}$ & 2789 & 5.3 & Low risk \\
\hline Adamson S., Lillian M. /2007[28] & Uganda & $\begin{array}{l}\text { Cross- } \\
\text { sectional }\end{array}$ & 2789 & 5.6 & Low risk \\
\hline $\begin{array}{l}\text { Mpabulungi L, } \\
\text { Mula AS/2006[27] }\end{array}$ & Uganda & $\begin{array}{c}\text { Cross- } \\
\text { sectional }\end{array}$ & 1528 & 21.9 & Low risk \\
\hline Nebiyu D. et al/2014[24] & Ethiopia & $\begin{array}{l}\text { Cross- } \\
\text { sectional }\end{array}$ & 1673 & 17.2 & Low risk \\
\hline Yousif M. et al/2012[25] & Sudan & $\begin{array}{l}\text { Cross- } \\
\text { sectional }\end{array}$ & 910 & 13.6 & Low risk \\
\hline Adamson S. et al/2011[29] & Tanzania & $\begin{array}{l}\text { Cross- } \\
\text { sectional }\end{array}$ & 1947 & 4 & Low risk \\
\hline
\end{tabular}

TABLE 2: Sensitivity analysis of the prevalence of cigarette smoking among school-going adolescents.

\begin{tabular}{lc}
\hline Study omitted & $\begin{array}{c}\text { Prevalence of current cigarette } \\
\text { smoking }(95 \% \mathrm{CI})\end{array}$ \\
\hline William K.et al/2007 & $8.94(6.0,11.8)$ \\
Ayalu A.et al/2012 & $9.57(6.6,12.5)$ \\
Emmanuel R. et al/2007 & $9.71(6.8,12.5)$ \\
Anteneh M. et al/2012 & $9.26(6.3,12.1)$ \\
Lilian M. et al/2004 & $9.4(6.4,12.5)$ \\
Adamson S, Lillian M. /2007 & $9.4(6.3,12.4)$ \\
Mpabulungi L, Mula AS/2006 & $7.6(5.2,9.7)$ \\
Nebiyu D. et al/2014 & $8.1(5.5,10.7)$ \\
Yousif M. et al/2012 & $8.1(5.0,11.1)$ \\
Adamson S. et al/2011 & $8.5(5.7,11.3)$ \\
Combined & $9.6(6.6,12.5)$ \\
\hline
\end{tabular}

\section{Results}

3.1. Literature Search and Selection of Eligible Material. A total of 925 original articles were identified from PubMed, Google Scholar, and the Web of Science Library. Out of all identified studies, 238 were found duplicated. Out of 687 studies, 536 were excluded based on the screening of titles and abstracts. Again, 76 studies were excluded owing to being studies conducted outside East African countries. Finally, ten articles were used for meta-analysis (Figure 1).

3.2. Characteristics of Included Studies. Ten studies were conducted in East African countries between 2003 and 2014. Of these, four were in Ethiopia [21-23, 36], three in Uganda
$[19,28,29]$, and one each in Kenya [25], Sudan [24], and Tanzania [26]. All of the studies accessed through the search were cross-sectional. Sample sizes ranged from 651 [21] to 12,378 [25] (Table 1).

3.3. Quality of Included Studies. Based on the JBI critical appraisal checklist for analytical cross-sectional studies, all of the papers had no methodological defect and significant risk of bias. Hence, no article was excluded from the metaanalysis.

\subsection{Meta-Analysis}

3.4.1. Prevalence of Current Cigarette Smoking. The combined prevalence of current cigarette smoking was found to be 9.02\% (95\% CI: 6.34-11.70; I2 =98.7\%, $P$ value $<0.001)$ among school adolescents in East Africa (Figure 2).

3.4.2. Subgroup Analysis. Subgroup analysis based on the country, where the studies were conducted, was done. The result revealed that the prevalence of current cigarette smoking among school-going adolescents was 9.8\% in Kenya, $7.72 \%$ in Ethiopia, $10.83 \%$ in Uganda, $13.6 \%$ in Sudan, and 4\% in Tanzania (Figure 3).

3.4.3. Sensitivity Analysis. The sensitivity analysis showed that there was little change that could not affect the overall outcome estimate too much (Table 2).

3.4.4. Publication Bias. A funnel plot was employed to see the symmetry of publications (Figure 4), and Egger's test showed no publication bias $(P$ value $=0.604)$. 


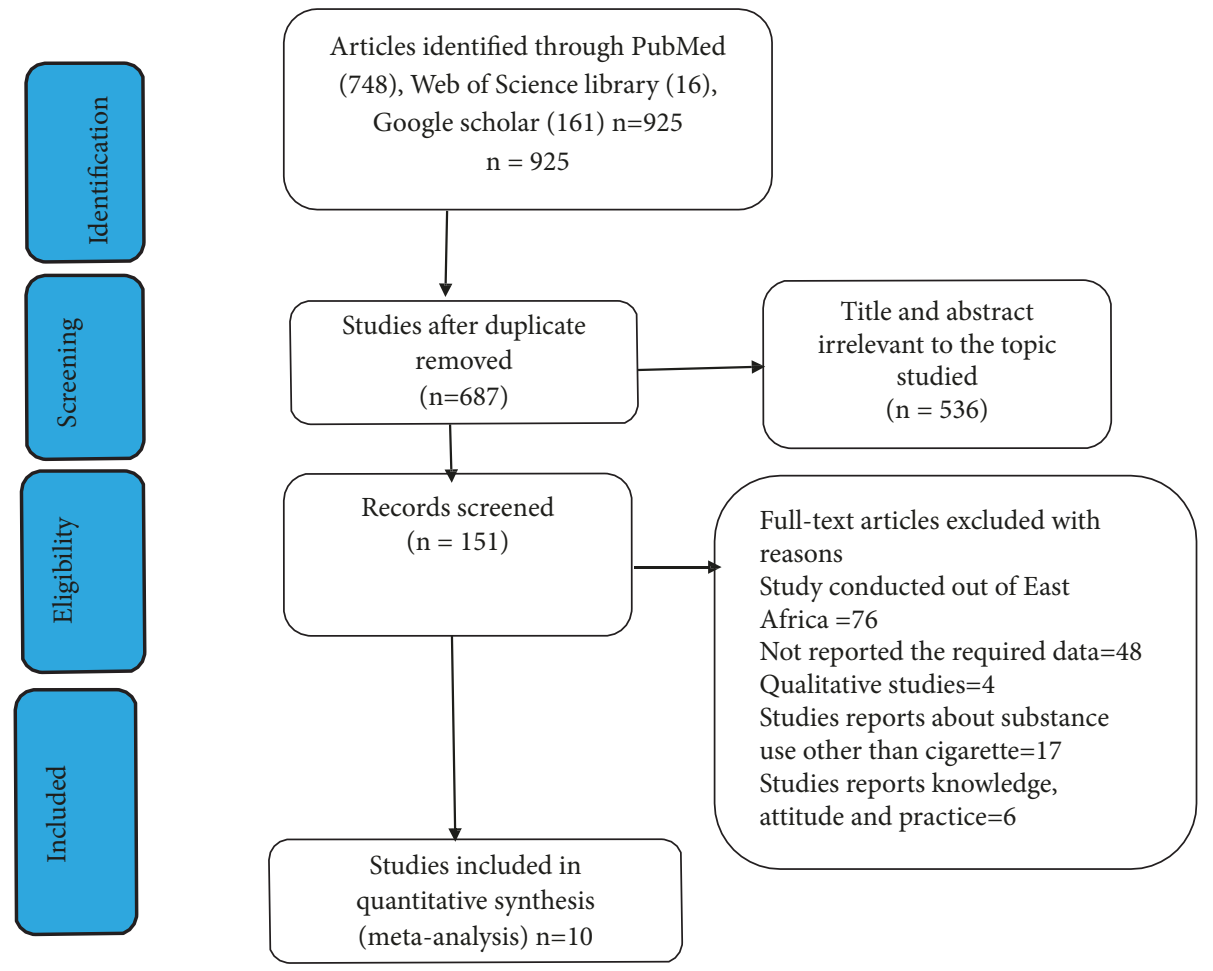

FIGURE 1: PRISMA flow diagram of identification and selection of studies for this systematic review and meta-analysis.

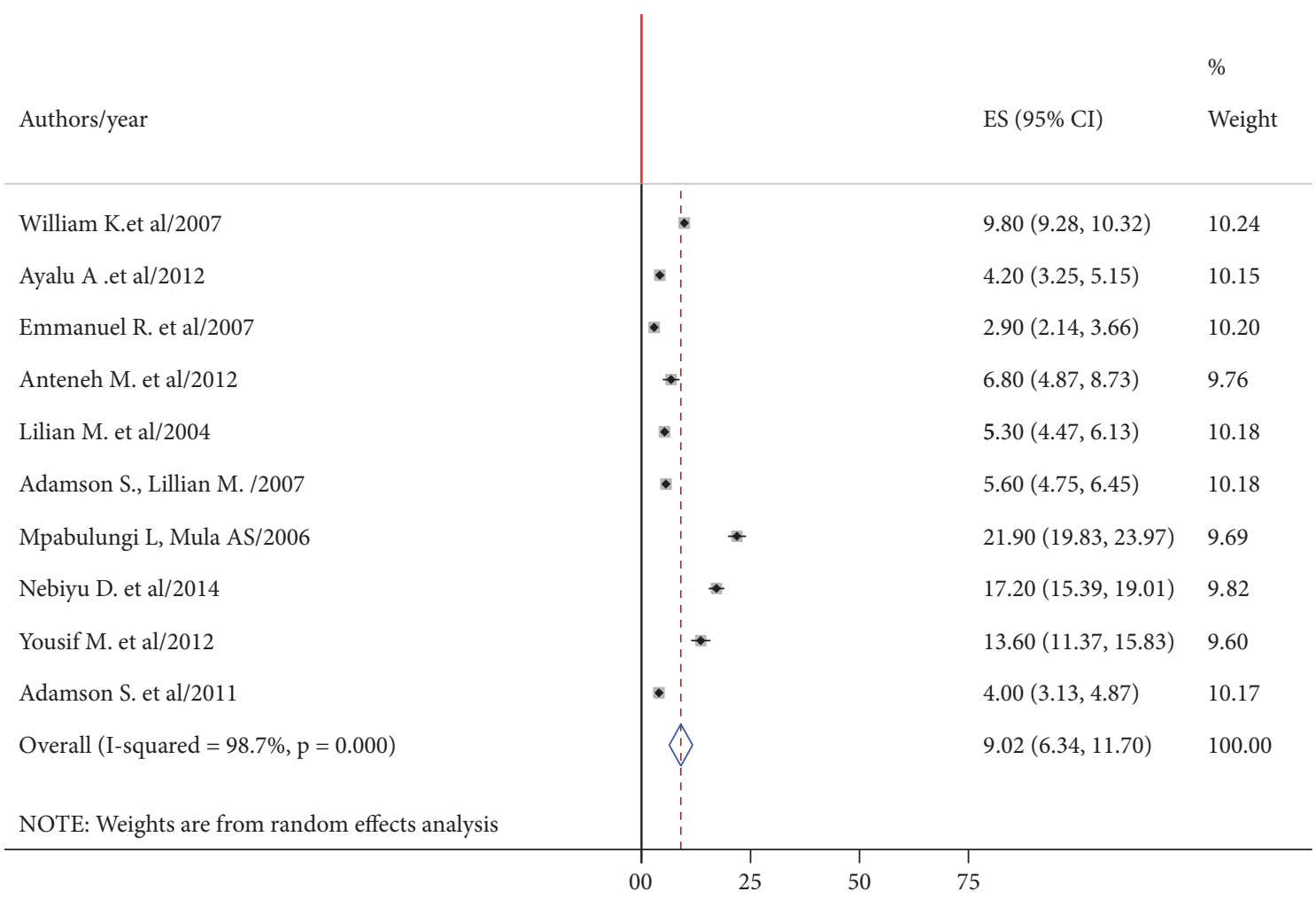

FIGURE 2: Forest plot of the pooled estimates (ES) cigarette smoking among school-going adolescents. The midpoint and the length of each segment indicated prevalence and a 95\% CI, whereas the diamond shape showed the combined prevalence of all studies. 


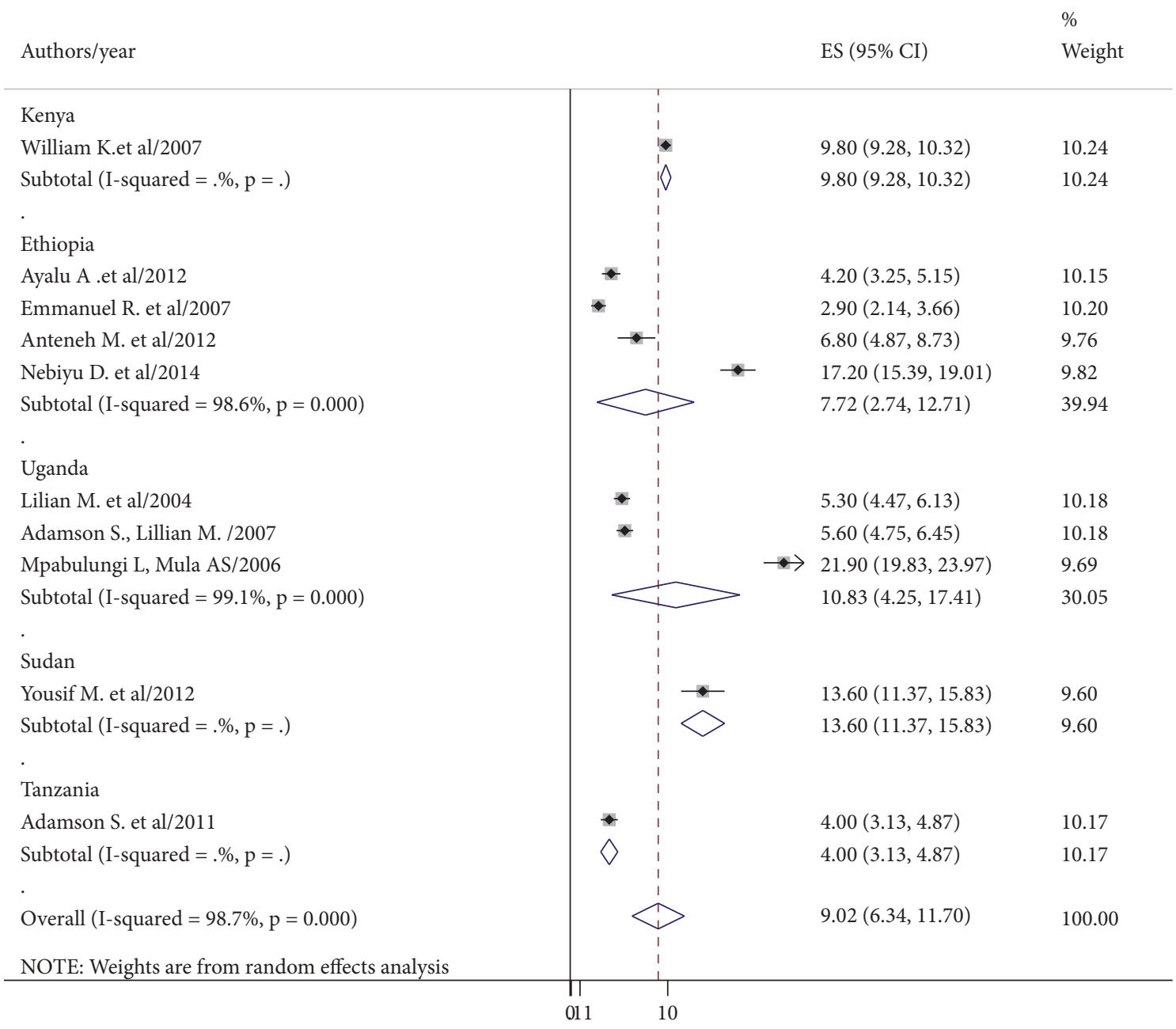

FIGURE 3: The forest plot showed the subgroup analysis of the prevalence (ES) of cigarette smoking among school-going adolescents. The midpoint and the length of each segment indicated prevalence and a 95\% CI, whereas the diamond shape showed the combined prevalence of all studies.

3.4.5. Predisposing Factors to Current Cigarette Smoking. According to the review, ten predictors were found to be significantly associated with cigarette smoking among schoolgoing adolescents (Table 3 ).

\section{Discussion}

Adolescence is a critical period of a developmental milestone, in which a significant number of smokers are initiated to smoke [5] and the gateway to other risky behaviors, like drug use. This systemic review and meta-analysis was conducted to estimate the pooled prevalence and associated factors of current cigarette smoking among school-going adolescents in East Africa. The pooled prevalence of the practice among the adolescents in East Africa was 9.02\% (95\%CI: 6.3411.70). This finding is congruent to those of studies done in Botswana (10\%) [37] and Brazil (10.7\%) [38]. In this setting, many people were living in the category of low socioeconomic status. Smoking prevalence was found to be higher among low socioeconomic status groups compared with their counterpart [39]. On the other hand, the current finding is higher than the prevalence reported in Bangladesh (2\%) [37], Iran (2.7\%) [38], Nigeria (4.2\%) [39], and China (7.93\%) [40]. This could be due to the fact that there were either ban or only partial ban policy implementations on cigarette sale promotion $[41,42]$ and owing to, perhaps, more exposure to tobacco advertisements $[43,44]$ in East African countries. In addition, the absence of school-based antismoking campaigners including trained teachers, lacking tobacco prevention initiatives, like social competence and influence interventions in schools, and the nonexistence of family-based interventions deserve blames. The implementation of these interventions helps adolescents to reduce experimentation with smoking by $16 \%$ to $32 \%$ [45]. Besides, lack of cigarette access restriction and sale prevention policies and smoking cessation program contributes to the high proportion of smoker adolescents in East African countries [46-48].

The finding of the current study is lower than those of studies done in Brazil 13.0\% [49], Pakistan (13.7\%) [50], 
TABLE 3: Associated factors of current cigarette smoking among school adolescents in East Africa.

\begin{tabular}{|c|c|c|}
\hline Sr. No. & $\begin{array}{l}\text { Sociodemographic related } \\
\text { factors }\end{array}$ & Associated factors \\
\hline 1 & Sex of students & Male had higher odds of smoking compared to female \\
\hline 2 & Age of students & Higher age was found to be a significant predictor of smoking \\
\hline 3 & Peer influence & $\begin{array}{l}\text { Having peer friends who smoke cigarette was found to be a } \\
\text { significant predictor of smoking }\end{array}$ \\
\hline 4 & $\begin{array}{l}\text { Perception of risk of } \\
\text { smoking }\end{array}$ & $\begin{array}{l}\text { Harmful perception about risk of smoking was negatively } \\
\text { associated with smoking cigarette }\end{array}$ \\
\hline 5 & Family's substance use & $\begin{array}{l}\text { History of substance use among family was positive associated } \\
\text { factor with cigarette smoking of adolescent }\end{array}$ \\
\hline 6 & Sibling's substance use & $\begin{array}{c}\text { Sibling's substance use was a significant predictor of substance } \\
\text { use }\end{array}$ \\
\hline 7 & $\begin{array}{l}\text { Owning an item with a } \\
\text { cigarette brand log }\end{array}$ & $\begin{array}{l}\text { Current cigarette smokers were more likely to have an item with } \\
\text { a cigarette logo compared to cigarette nonsmokers, OR } 2.0(95 \% \\
\text { CI: } 1.1-3.5) \text {. }\end{array}$ \\
\hline 8 & $\begin{array}{l}\text { Exposure to movie with } \\
\text { actors smoking }\end{array}$ & $\begin{array}{c}\text { Adolescents who were exposed to movies whose actors are } \\
\text { smokers were seen } 2.8 \text { times more likely to use tobacco (AOR = } \\
\qquad 2.84,95 \% \text { CI 1.703-11.116) }\end{array}$ \\
\hline 9 & $\begin{array}{l}\text { Exposure to antismoking } \\
\text { media message }\end{array}$ & $\begin{array}{c}\text { Adolescents who were not exposed to antismoking media } \\
\text { messages on television, radio, newspaper or magazines were } \\
\text { seen more likely to use tobacco than those who were exposed } \\
(\text { AOR }=4.43,95 \% \text { CI } 1.838-7.13)\end{array}$ \\
\hline
\end{tabular}

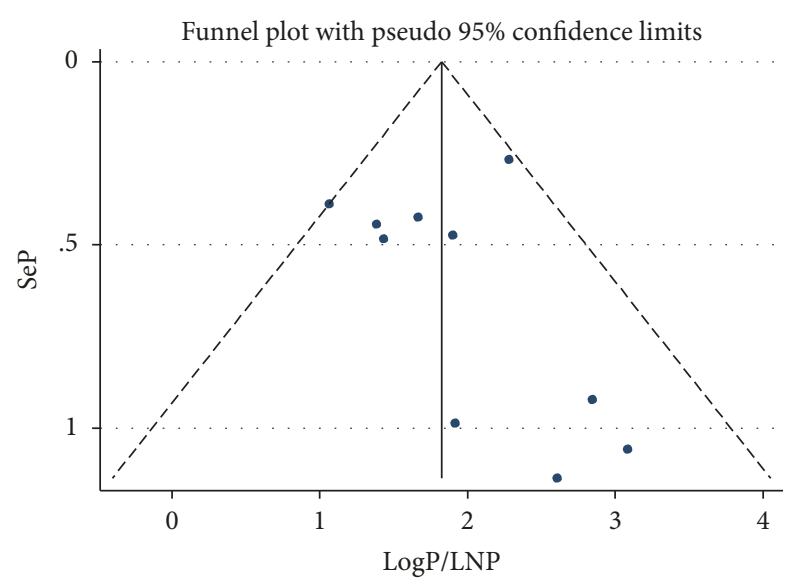

FIGURE 4: Funnel plot vertical lines estimate the effect size, whereas a diagonal line measures the precision of individual studies with a $95 \%$ confidence limit.

and China $14.12 \%$ [51]. This difference might be due to the fact that some indigenous cultures allow adolescents to access cigarette or tobacco as well as differences in religious teachings.

The subgroup analysis showed that the prevalence of the current cigarette smoking in Sudan (13.6\%) was similar to that of Uganda (11.21\%) and Kenya (9.8\%). A large proportion of the adolescents lived in low-income countries of northeast Africa. As a result, tobacco companies' shifted their production to this region because of the existence of cheap child labor for tobacco cultivation and picking and the availability of large-scale tobacco farms. However, the result was higher than that of Tanzania (4\%) and Ethiopia (7.72\%). The possible explanation for this variation may be the socioeconomic status of individual, communities differences in the social norms, high production of tobacco at local community level as small-scale farming for income generation, sample size differences, and incoherent tobacco control and prevention policies of the countries.

In East African countries, having peers who smoke tobacco was significantly associated with being smokers. This result was consistent with those of Pakistan, Turkey, and Saudi Arabia which were [50, 52, 53], respectively. This could be because early adolescents psychologically consider themselves as unique and invulnerable, they experience a sense of separation or independence as a developmental task, and they spend plenty of their time with many peers. In due course, this "personal fable" leads to detachment of adolescents from their family ties or parental values.

Male sex [54-56] was a predisposing factor to cigarette smoking. This could be related to the fact that males are not socially sanctioned as females. As well, having multiple partners is a prescribed and socially accepted and expected role of the male in some East African countries.

Having family members who smoked $[50,52,53,57]$ had also predisposed school-going adolescents to the habit. This may be because families are the primary sources of reinforcement, and adolescents whose fathers were in the lowest occupational groups were two times as likely to those whose fathers occupying the highest occupational status.

Exposure to movies with smoking actors, having some pocket money, and not discussing in class about the dangers of smoking were notable predisposing factors [52]. This is because health education and antismoking sessions were not 
incorporated in the primary and secondary school curricula. Due to this, adolescents could not improve their knowledge, modify their attitude, and decide to quit smoking.

\section{Limitation of This Study}

Though this review is the first systematic review and metaanalysis done in East Africa, it has its own limitation. No studies were found in all East African countries. Besides, we may missed studies conducted other than in English language.

\section{Conclusions}

The finding of this meta-analysis revealed that the prevalence of cigarette smoking was increasing among school-going adolescents in East Africa at the moment, and various risk factors are responsible for the exposure. Therefore, countries have to realize sale prevention policies, implement antismoking campaigners, emphasize health hazard adverts about cigarettes, and integrate health education on cigarettes in youth-friendly services.

\section{Abbreviations \\ JBI: Joanna Briggs Institute \\ HIV/AIDS: Human immunodeficiency virus/acquired immunodeficiency syndrome \\ PRISMA-P: Preferred items for systemic reviews and meta-analysis protocol.}

\section{Data Availability}

All data are available within the paper.

\section{Conflicts of Interest}

The authors have declared that there are no conflicts of interest.

\section{Authors' Contributions}

Nega Tezera is a principal investigator of this study and he had taken responsibility for the conception of the idea, designing the study, extraction of the data, performing meta-analysis and interpretation of data, drafting the paper, and revising the manuscript. Aklilu Endalamaw is the second author and he had performed meta-analysis and interpretation of data, revised the manuscript critically, and approved the final version of the paper before publication.

\section{Acknowledgments}

We would like to thank Mr. Mequanent Kassa for his support on meta-analysis.

\section{References}

[1] “Tobacco," http://www.who.int/news-room/fact-sheets/detail/ tobacco.

[2] WHO, WHO Report on the Global Tobacco Epidemic, WHO, 2015, http://www.who.int/tobacco/global_report/2015/en/.

[3] J. Collin, "Global health, equity and the WHO framework convention on tobacco control," Global Health Promotion, vol. 17, no. 1, pp. 73-75, 2010.

[4] E. M. Nturibi, A. A. Kolawale, and S. A. McCurdy, "Smoking prevalence and tobacco control measures in Kenya, Uganda, the Gambia, and Liberia: a review," International Journal of Tuberculosis and Lung Disease, vol. 13, no. 2, pp. 165-170, 2009.

[5] National Center for Chronic Disease Prevention and Health Promotion (US) Office on Smoking and Health, Preventing Tobacco Use among Youth and Young Adults: A Report of the Surgeon General, Centers for Disease Control and Prevention (US), Atlanta, USA, 2012, https://www.ncbi.nlm.nih.gov/ books/NBK99237/.

[6] National Center for Chronic Disease Prevention and Health Promotion (US) Office on Smoking and Health, The Health Consequences of Smoking-50 Years of Progress: A Report of the Surgeon General, Centers for Disease Control and Prevention (US), Atlanta, USA, 2014, http://www.ncbi.nlm.nih.gov/books/NBK179276/.

[7] J. M. McGinnis and W. H. Foege, "Actual causes of death in the United States," JAMA, vol. 270, no. 18, pp. 2207-2212, 1993.

[8] I. S. Ockene and N. H. Miller, "Cigarette smoking, cardiovascular disease, and stroke: a statement for healthcare professionals from the American Heart Association. American Heart Association Task Force on Risk Reduction," Circulation, vol. 96, no. 9, pp. 3243-3247, 1997.

[9] N. J. Wald and A. K. Hackshaw, "Cigarette smoking: an epidemiological overview," British Medical Bulletin, vol. 52, no. 1, pp. 3-11, 1996.

[10] T. T. Amin, M. A. M. Amr, and B. O. Zaza, "Psychosocial predictors of smoking among secondary school students in AlHassa, Saudi Arabia," Journal of Behavioral Medicine, vol. 34, no. 5, pp. 339-350, 2011.

[11] M. J. Elders, C. L. Perry, M. P. Eriksen, and G. A. Giovino, "The report of the Surgeon General: preventing tobacco use among young people," American Journal of Public Health, vol. 84, no. 4, pp. 543-547, 1994.

[12] N. Z. Weinberg, E. Rahdert, J. D. Colliver, and M. D. Glantz, "Adolescent substance abuse: A review of the past 10 years," Journal of the American Academy of Child and Adolescent Psychiatry, vol. 37, no. 3, pp. 252-261, 1998.

[13] R. A. Arrazola, L. J. Neff, S. M. Kennedy et al., "Tobacco use among middle and high school students- the United States," Morbidity and Mortality Weekly Report, vol. 63, no. 45, 2014.

[14] V. U. Ekpu and A. K. Brown, "The economic impact of smoking and of reducing smoking prevalence: review of evidence," Tobacco Use Insights, vol. 8, pp. 1-35, 2015.

[15] A. L. C. Hallal, S. L. D. Gotlieb, L. M. de Almeida, and L. Casado, "Prevalence and risk factors associated with smoking among school children, Southern Brazil," Revista de Saúde Pública, vol. 43 , no. 5, pp. 779-788, Oct 2009.

[16] H. Huang, C. Lu, Y. Yang, and C. Huang, "Smoking behaviours of adolescents, influenced by smoking of teachers, family and friends," International Nursing Review, vol. 61, no. 2, pp. 220 227,2014 
[17] K. Peltzer, "Early smoking initiation and associated factors among in-school male and female adolescents in seven African countries," African Health Sciences, vol. 11, no. 3, pp. 320-328, 2011.

[18] A. V. Prokhorov, J. P. Winickoff, J. S. Ahluwalia et al., "Youth tobacco use: A global perspective for child health care clinicians," Pediatrics, vol. 118, no. 3, pp. e890-e903, 2006.

[19] A. S. Muula and L. Mpabulungi, "Cigarette smoking prevalence among school-going adolescents in two African capital cities: Kampala Uganda and Lilongwe Malawi," African Health Sciences, vol. 7, no. 1, pp. 45-49, 2007.

[20] A. A. Reda, A. Moges, B. Yazew, and S. Biadgilign, "Determinants of cigarette smoking among school adolescents in eastern Ethiopia: a cross-sectional study," Harm Reduction Journal, 2012.

[21] A. M. Birhanu, T. A. Bisetegn, and S. M. Woldeyohannes, "High prevalence of substance use and associated factors among high school adolescents in Woreta Town, Northwest Ethiopia: multidomain factor analysis," BMC Public Health, vol. 14, no. 1, 2014.

[22] E. Rudatsikira, A. Abdo, and A. S. Muula, "Prevalence and determinants of adolescent tobacco smoking in Addis Ababa, Ethiopia," BMC Public Health, vol. 7, p. 176, 2007.

[23] N. D. Sabit Abazinab, "Prevalence and predictors of cigarette smoking among adolescents of Ethiopia: school based cross sectional survey," Journal of Child and Adolescent Behaviour, vol. 03, no. 01, 2015.

[24] Y. M. Gadalla, A-M. Adil, B. M. Mustafa, and H. Abdo, "Prevalence of smoking among school adolescents in Khartoum State," Sudanese Journal of Paediatrics, vol. 12, no. 2, pp. 44-48, 2012.

[25] W. K. Maina, J. N. Nato, M. A. Okoth, D. J. Kiptui, and A. O. Ogwell, "Prevalence of tobacco use and associated behaviours and exposures among the youth in Kenya: report of the global youth tobacco survey in 2007," Public Health Research, vol. 3, no. 3, pp. 43-49, 2013.

[26] A. Kapito-Tembo, A. S. Muula, E. Rudatsikira, and S. Siziya, "Smoking among in-school adolescents in Dar Es Salaam, Tanzania: results from the Global Youth Tobacco Survey," Tanzania Journal of Health Research, vol. 13, no. 3, pp. 196-204, 2011.

[27] M. J. Elders, C. L. Perry, M. P. Eriksen, and G. A. Giovino, "The report of the surgeon general: Preventing tobacco use among young people," American Journal of Public Health, vol. 84, no. 4, pp. 543-547, 1994.

[28] L. Mpabulungi and A. S. Muula, "Tobacco use among high school students in a remote district of Arua, Uganda," Rural and Remote Health, vol. 6, no. 4, p. 609, 2006.

[29] L. Mpabulungi and A. S. Muula, "Tobacco use among high school students in Kampala, Uganda: questionnaire study," Croatian Medical Journal, vol. 45, no. 1, pp. 80-83, 2004.

[30] L. H. Poulsen, M. Osler, C. Roberts, P. Due, M. T. Damsgaard, and B. E. Holstein, "Exposure to teachers smoking and adolescent smoking behaviour: Analysis of cross sectional data from Denmark," Tobacco Control, vol. 11, no. 3, pp. 246-251, 2002.

[31] D. Moher, A. Liberati, J. Tetzlaff, and D. G. Altman, "Preferred reporting items for systematic reviews and meta-analyses: the prisma statement," Plos Med, vol. 6, no. 7716, pp. 1-15, 2009.

[32] The Joanna Briggs Institute, The Joanna Briggs Institute Reviewers' Manual 2015: Methodology for JBI scoping Reviews, Joanne Briggs Inst, 2015.
[33] R. DerSimonian and R. Kacker, "Random-effects model for meta-analysis of clinical trials: an update," Contemporary Clinical Trials, vol. 28, no. 2, pp. 105-114, 2007.

[34] J. P. T. Higgins, S. G. Thompson, J. J. Deeks, and D. G. Altman, "Measuring inconsistency in meta-analyses," British Medical Journal, vol. 327, no. 7414, pp. 557-560, 2003.

[35] J. L. Peters, A. J. Sutton, D. R. Jones et al., "Comparison of two methods to detect publication bias in meta-analysis," JAMA, vol. 295, no. 6, pp. 676-680, 2006.

[36] A. A. Reda, A. Moges, B. Yazew, and S. Biadgilign, "Determinants of cigarette smoking among school adolescents in eastern Ethiopia: a cross-sectional study," Harm Reduction Journal, vol. 9, article 39, 2012.

[37] B. Mbongwe, R. Tapera, N. Phaladze, A. Lord, and N. M. Zetola, "Predictors of smoking among primary and secondary school students in Botswana," Plos One, vol. 12, no. 4, Article ID e0175640, 2017.

[38] V. C. Barbosa Filho, W. d. Campos, and A. d. Lopes, "Prevalence of alcohol and tobacco use among Brazilian adolescents: a systematic review," Revista de Saúde Pública, vol. 46, no. 5, pp. 901-917, 2012.

[39] D. Doku, L. Koivusilta, S. Raisamo, and A. Rimpelä, "Do socioeconomic differences in tobacco use exist also in developing countries? A study of Ghanaian adolescents," BMC Public Health, vol. 10, no. 1, p. 758, 2010.

[40] M. Wang, J. Zhong, L. Fang, and H. Wang, "Prevalence and associated factors of smoking in middle and high school students: a school-based cross-sectional study in Zhejiang Province, China," BMJ Open, vol. 6, no. 1, Article ID e010379, 2016.

[41] M. K. Rimpelä, L. E. Aarø, and A. H. Rimpelä, “The effects of tobacco sales promotion on initiation of smoking-experiences from Finland and Norway," Scandinavian Journal of Social Medicine. Supplementum, vol. 49, pp. 5-23, 1993.

[42] A. S. Madkour, E. C. Ledford, L. Andersen, and C. C. Johnson, "Tobacco advertising/promotions and adolescents' smoking risk in Northern Africa," Tobacco Control, vol. 23, no. 3, pp. 244252, 2014.

[43] C. Lovato, A. Watts, and L. F. Stead, "Impact of tobacco advertising and promotion on increasing adolescent smoking behaviours," Cochrane Database of Systematic Reviews (Online), no. 10, Article ID CD003439, 2011.

[44] L. M. English, J. Hsia, and A. Malarcher, "Tobacco advertising, promotion, and sponsorship (TAPS) exposure, anti-TAPS policies, and students' smoking behavior in Botswana and South Africa," Preventive Medicine, vol. 91, pp. S28-S34, 2016.

[45] R. E. Thomas, P. R. A. Baker, B. C. Thomas, and D. L. Lorenzetti, "Family-based programmes for preventing smoking by children and adolescents," Cochrane Database of Systematic Reviews, no. 2, Article ID CD004493, 2015.

[46] F. J. Chaloupka, "Contextual factors and youth tobacco use: Policy linkages," Addiction, vol. 98, no. 1, pp. 147-149, 2003.

[47] P. A. Cavazos-Rehg, M. J. Krauss, S. J. Sowles et al., "Multiple levels of influence that impact youth tobacco use," Tobacco Regulatory Science, vol. 2, no. 2, pp. 106-122, 2016.

[48] L. Liang, F. Chaloupka, M. Nichter, and R. Clayton, "Prices, policies and youth smoking, May 2001," Addiction, vol. 98, no. 1, pp. 105-122, 2003.

[49] M. Urrutia-Pereira, V. J. Oliano, C. S. Aranda, J. Mallol, and D. Solé, "Prevalence and factors associated with smoking among adolescents," Jornal de Pediatria, vol. 93, no. 3, pp. 230-237, 2017. 
[50] S. Rozi, S. Akhtar, S. Ali, and J. Khan, "Prevalence and factors associated with current smoking among high school adolescents in Karachi, Pakistan," Southeast Asian Journal of Tropical Medicine and Public Health, vol. 36, no. 2, pp. 498-504, 2005.

[51] J. Han and X. Chen, "A meta-analysis of cigarette smoking prevalence among adolescents in China: 1981-2010," International Journal of Environmental Research and Public Health, vol. 12, no. 5, pp. 4617-4630, 2015.

[52] N. Ertas, "Factors associated with stages of cigarette smoking among Turkish youth," European Journal of Public Health, vol. 17, no. 2, pp. 155-161, 2007.

[53] H. Al Mohamed and T. Amin, "Pattern and prevalence of smoking among students at King Faisal University, Al Hassa, Saudi Arabia," Eastern Mediterranean Health Journal, vol. 16, no. 01, pp. 56-64, 2010.

[54] K. Polańska, P. Wojtysiak, L. Bak-Romaniszyn, and D. Kaleta, "Susceptibility to cigarette smoking among secondary and high school students from a socially disadvantaged rural area in Poland," Tobacco Induced Diseases, vol. 14, no. 1, p. 28, 2016.

[55] D. Hammond, F. Kin, A. Prohmmo et al., "Patterns of smoking among adolescents in Malaysia and Thailand: Findings from the International Tobacco Control Southeast Asia Survey," AsiaPacific Journal of Public Health, vol. 20, no. 3, pp. 193-203, 2008.

[56] T. Bandason and S. Rusakaniko, "Prevalence and associated factors of smoking among secondary school students in Harare Zimbabwe," Tobacco Induced Diseases, vol. 8, no. 1, p. 12, 2010.

[57] K. Lochbuehler, K. Schuck, R. Otten, L. Ringlever, and M. Hiemstra, "Parental smoking and smoking cognitions among youth: A systematic review of the literature," European Addiction Research, vol. 22, no. 4, pp. 215-232, 2016. 


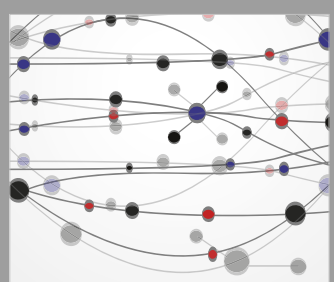

The Scientific World Journal
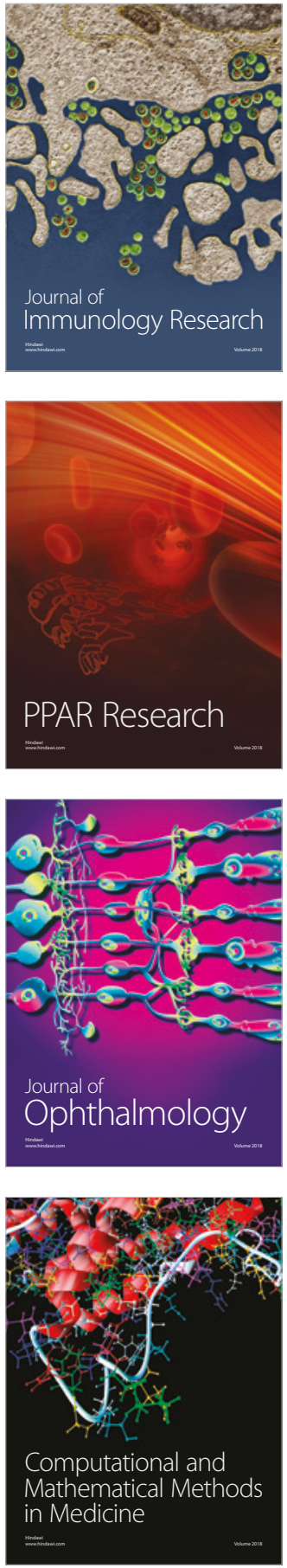

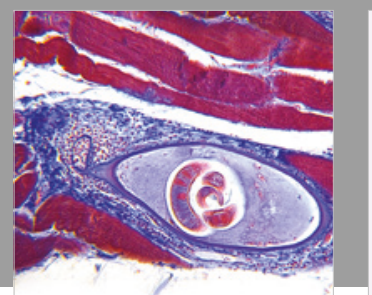

Gastroenterology Research and Practice

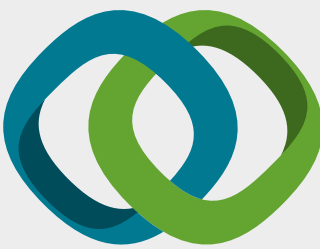

\section{Hindawi}

Submit your manuscripts at

www.hindawi.com
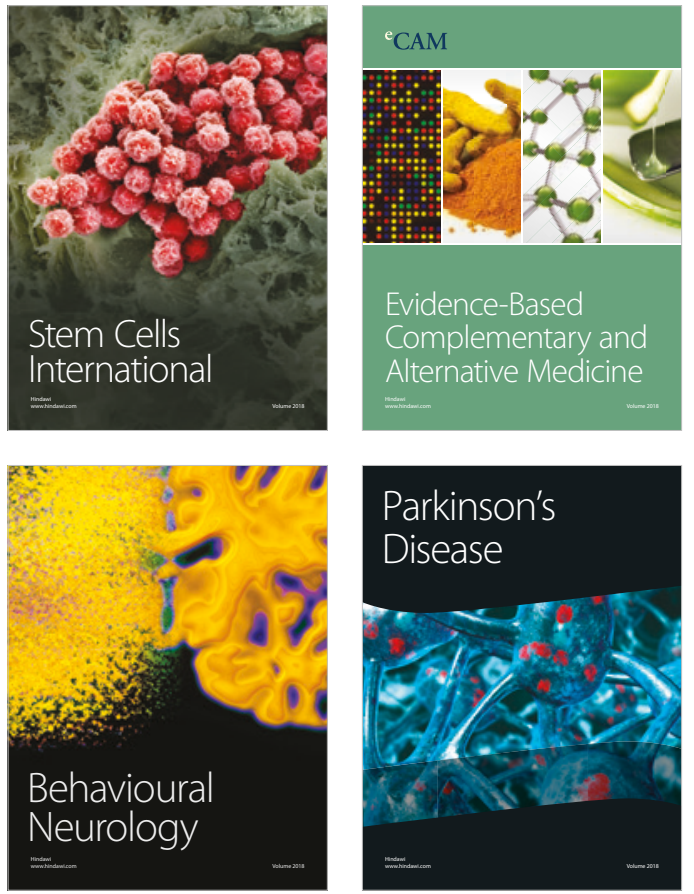

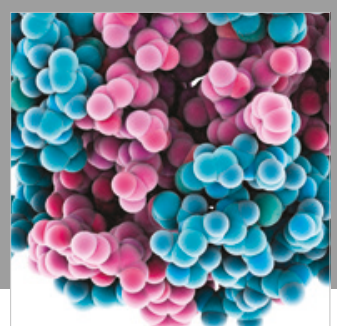

ournal of

Diabetes Research

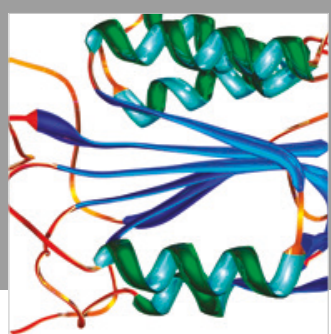

Disease Markers
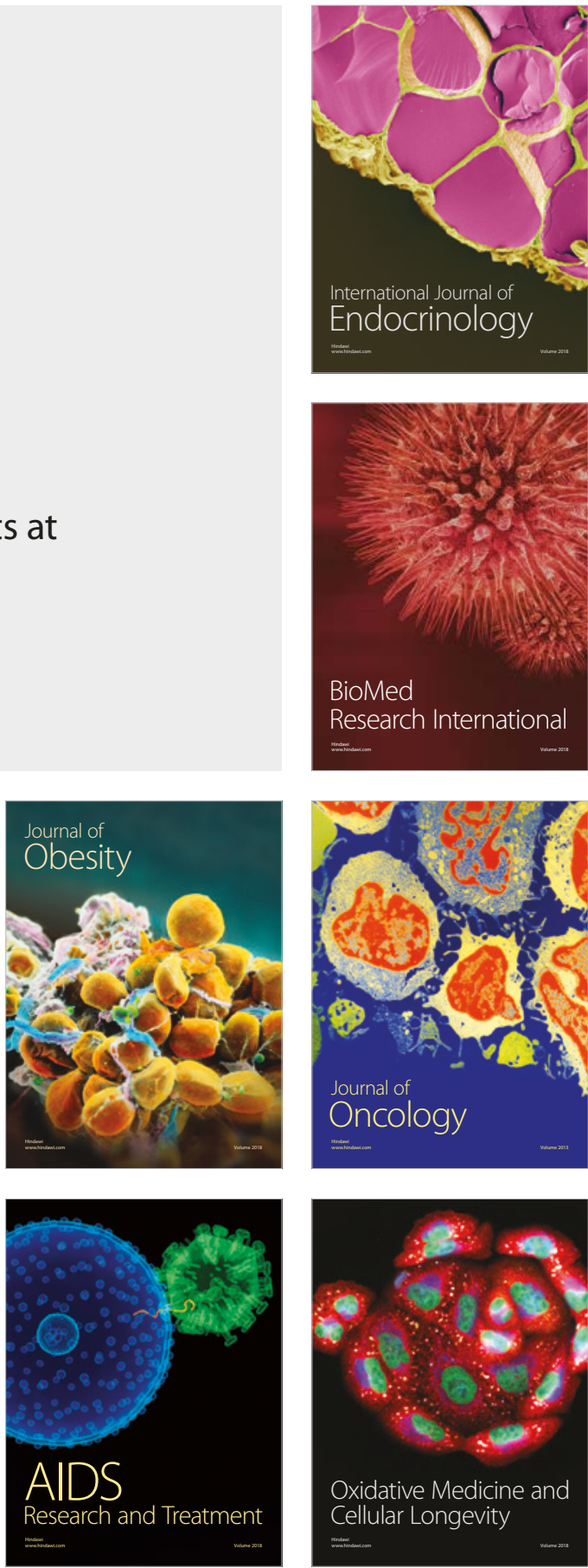